\title{
Impact of Sexual Abuse on Children: A Review and Synthesis of Recent Empirical Studies
}

\author{
Kathleen A. Kendall-Tackett, Linda Meyer Williams, and David Finkelhor
}

\begin{abstract}
A review of 45 studies clearly demonstrated that sexually abused children had more symptoms than nonabused children, with abuse accounting for $15-45 \%$ of the variance. Fears, posttraumatic stress disorder, behavior problems, sexualized behaviors, and poor self-esteem occurred most frequently among a long list of symptoms noted, but no one symptom characterized a majority of sexually abused children. Some symptoms were specific to certain ages, and approximately one third of victims had no symptoms. Penetration, the duration and frequency of the abuse, force, the relationship of the perpetrator to the child, and maternal support affected the degree of symptomatology. About two thirds of the victimized children showed recovery during the first 12-18 months. The findings suggest the absence of any specific syndrome in children who have been sexually abused and no single traumatizing process.
\end{abstract}

Until recently, the literature on the impact of child sexual abuse consisted disproportionately of retrospective studies of adults. For example, the conclusions of a widely cited review (Browne \& Finkelhor, 1986) were based on only 4 studies of children, compared with 23 studies of adults. Not surprisingly, most reviews combined studies of both groups, because research focused on children was rare.

Since 1985, however, there has been an explosion in the number of studies that have concentrated specifically on sexually abused children. Some studies have even focused on specific types of child victims, such as preschoolers, boys, or victims of ritualistic abuse. The studies of child victims have been distinct in several important ways from the research on adults. First, researchers studying children have of ten used different methodologies, many times relying on parents' or clinicians' reports rather than on children's self-reports. In addition, they have often evaluated specifically child-oriented symptoms, such as regressive behavior. These methodologies and the concentration on child-oriented symptoms make this research more relevant to intervention and treatment with children than the research on the effects of sexual abuse on adults, from which the

Kathleen A. Kendall-Tackett, Linda Meyer Williams, and David Finkelhor, Family Research Laboratory, University of New Hampshire.

This article is based on a paper presented at the meetings of the American Professional Society on the Abuse of Children, January 1991, San Diego, California. The present research was carried out with funds provided by National Institute of Mental Health Grant T32 MH15161 and National Center for Child Abuse and Neglect Grant 90CA 1406. We thank Elizabeth Royal and Patricia VanWagoner for assistance in preparing the manuscript. We also thank members of the 1991 Family Violence Seminar and the anonymous reviewers for their helpful comments

Correspondence concerning this article should be addressed to Kathleen A. Kendall-Tackett, now at the Stone Center for Developmental Services and Studies, Wellesley College, Wellesley, Massachusetts 02181 . implications for the treatment of children were difficult to extrapolate.

Research on children has allowed for a developmental perspective and included the first efforts at longitudinal studies of sexual abuse victims. This literature also has important relevance to other theory and research concerning how children process trauma, for example, how trauma expresses itself at various developmental stages, its role in the development of later psychopathology, and the mediating effects of important factors such as familial and community support. Therefore, research on the effect of sexual abuse on children is worthy of its own review.

We undertook such a review to (a) bring together literature from a broad spectrum of fields, including medicine, social work, psychology, and sociology; (b) highlight areas where there is agreement and disagreement in findings; (c) draw conclusions that may be useful for clinicians currently working with child victims and researchers studying this problem; and (d) suggest directions for future research and theory.

\section{Domain}

In the present review, we included studies of child victims of sexual abuse, ${ }^{1}$ in which all subjects were 18 years of age or younger (see Appendix). In all of these studies, quantitative results of at least one of the following types were reported: a

\footnotetext{
' Note that when we refer to victims, we mean victims who have come to public attention. The findings from the present review cannot be generalized to unreported victims, for whom impact may be substantially different. In a controversial study of unreported victims from The Netherlands, Sandfort $(1982,1984)$ claimed that certain (primarily adolescent) boys had relationships with adult pedophiles that they described in positive terms and appeared to have no negative effects. Because these boys were nominated for the research by the pedophiles themselves, who were involved in a pedophile advocacy group, it is difficult to know to what group of children such findings could be generalized.
} 
comparison of sexually abused children with nonabused children or norms (clinical and/or nonclinical) or the age of victims who manifested some symptom. Certain other studies that did not contain these types of data, yet included other relevant data on intervening variables or longitudinal findings, are not listed in the Appendix but are referenced in the appropriate sections. The majority were published within the past 5 years. Because there has been so much research on this topic in the past few years, we also included some unpublished material (most of the manuscripts are currently under review), located through researchers who specialize in research in this area. Although we undoubtedly missed some articles, we are confident that we were able to locate most of them because of the network of researchers we contacted.

Excluded from the present review were nonquantitative or case studies. We also excluded studies in which all subjects manifested a certain behavior (such as teen prostitution or running away) but only some of them had been sexually abused. (In contrast, in the studies we included in the present review, all subjects had been abused.) Finally, we excluded studies that involved both adult and child victims (e.g., ages 15-45) and combined results from these two groups.

The studies used samples from several different sources, but primarily drew from sexual abuse evaluation or treatment programs. Some investigators recruited from specific subgroups of victims, such as day-care victims. Most investigators combined victims of intra- and extrafamilial abuse. The samples also included a wide variety of ages, covering the entire spectrum from preschool to adolescence. The sample sizes ranged from very small $(N=8)$ to large $(N=369)$, with the majority between 25 and 50 children. Approximately half $(55 \%)$ the studies included comparison groups, and six had both nonabused clinical and nonabused nonclinical controls. This is a major improvement over studies conducted even 10 years ago. The studies used a variety of sources for assessment, including parent report, chart review, clinician report, and children's self-report.

In reviewing these studies, we first looked at the findings with regard to symptoms and then examined the intervening variables that affected these symptoms. We then paid particular attention to the longitudinal studies undertaken thus far. Finally, we drew conclusions for theory and future research.

\section{Comparison of Abused and Nonabused Children}

A wide range of symptoms have been examined in the studies in which sexually abused children have been compared with nonabused clinical or nonclinical children (or norms). Table 1 groups these symptoms together under major headings. As shown in Column 1, by far the most commonly studied symptom was sexualized behavior, often considered the most characteristic symptom of sexual abuse. Sexualized behavior usually included such things as sexualized play with dolls, putting objects into anuses or vaginas, excessive or public masturbation, seductive behavior, requesting sexual stimulation from adults or other children, and age-inappropriate sexual knowledge (Beitchman, Zucker, Hood, daCosta, \& Akman, 1991). Other symptoms that appeared in many studies included anxiety, depression, withdrawn behavior, somatic complaints, aggression, and school problems.
Column 2 shows the number of studies in which sexually abused children were more symptomatic than their nonabused counterparts. The denominator is the number of studies in which this comparison was made. For many symptoms, a difference was found in all of the studies in which such a comparison was made. These symptoms were fear, nightmares, general posttraumatic stress disorder (PTSD), ${ }^{2}$ withdrawn behavior, neurotic mental illness, cruelty, delinquency, sexually inappropriate behavior, regressive behavior (including enuresis, encopresis, tantrums, and whining), running away, general behavior problems, self-injurious behavior, internalizing, and externalizing. ${ }^{3}$ The symptom with the lowest percentage of studies in which a difference was found (besides suicidal behavior, for which a difference was found in only one study) was poor selfesteem (50\%). This may be in part because poor self-esteem is so common and has so many possible causes. It may also be because this symptom was the one most frequently measured by child self-report, a method that may underestimate pathology (see Methodological Issues and Directions for Future Research). Nonetheless, for almost every symptom examined, including self-esteem, in most studies sexually abused children were found to be more symptomatic than their nonabused counterparts.

The comparison between sexually abused children and other clinical, nonabused children (i.e., children in treatment) tells a possibly different story, however (Columns 3-5). For many of the symptoms measured, sexually abused children were actually less symptomatic than these clinical children in the majority of the studies. Sexually abused children showed only two symptoms consistently more often than nonabused clinical children: PTSD (just one study) and sexualized behavior (six of eight studies). Thus, sexually abused children tended to appear less symptomatic than their nonabused clinical counterparts except in regard to sexualized behavior and PTSD. These results must be interpreted very cautiously, especially in the light of two features of the clinical comparison groups with which abused children were often compared. First, most clinical comparison groups of so-called nonabused children probably actually do contain children whose abuse simply has not been discovered. In this case, the comparison is not a true abused-versus-nonabused comparison. Second, clinical comparison groups generally contain many children who are referred primarily because of their symptomatic behavior. Naturally these children are likely to be more symptomatic than children referred not because of symptoms, but because of something done to them (i.e., abuse). Thus, the lower levels of symptoms in sexually abused children may say more about the clinical comparisons than about the sexually abused children themselves.

For a synthesis of findings such as in Table 1, a comparison of effect sizes would ordinarily be preferable to the so-called sim-

\footnotetext{
${ }^{2}$ In this article, we group posttraumatic stress disorder with symptoms even though we realize that it is a cluster of symptoms comprising a diagnostic category.

${ }^{3}$ Internalizing and externalizing are composite symptoms found on the Child Behavior Checklist (Achenbach \& Edelbrock, 1984). Internalizing is withdrawn behavior, depression, fearfulness, inhibition, and overcontrol. Externalizing includes aggression and antisocial and undercontrolled behavior.
} 
Table 1

Sexually Abused (SA) Versus Nonsexually Abused (NSA) Children: Nonclinical and Clinical Comparison Groups

\begin{tabular}{|c|c|c|c|c|c|c|}
\hline \multirow[b]{2}{*}{ Symptom } & \multicolumn{2}{|c|}{ Nonclinical } & \multicolumn{4}{|c|}{ Clinical } \\
\hline & $\begin{array}{c}\text { Total no. } \\
\text { studies }\end{array}$ & $\begin{array}{c}\mathrm{SA}>\mathrm{NSA}^{\mathrm{a}} / \\
\text { no. studies }\end{array}$ & $\begin{array}{l}\text { No. studies } \\
\text { in which } \\
\text { SA }>N_{S A} A^{a}\end{array}$ & $\begin{array}{c}\text { No. studies } \\
\text { in which there } \\
\text { was no difference }\end{array}$ & 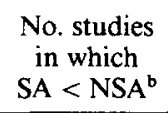 & $\begin{array}{c}\text { Total no. } \\
\text { studies }\end{array}$ \\
\hline Anxiety & 14 & $5 / 8$ & 1 & 2 & 0 & 3 \\
\hline Fear & 6 & $5 / 5$ & $i$ & 0 & 2 & 3 \\
\hline \multicolumn{7}{|l|}{ Posttraumatic stress disorder } \\
\hline Nightmares & 3 & $1 / 1$ & 1 & - & - & 1 \\
\hline General & 5 & $1 / 1$ & 1 & 0 & 0 & 1 \\
\hline \multicolumn{7}{|l|}{ Depression } \\
\hline Depressed & 17 & $10 / 11$ & 1 & 2 & 2 & 5 \\
\hline Withdrawn & 14 & $11 / 11$ & 1 & 1 & 3 & 5 \\
\hline Suicidal & 7 & $0 / 1$ & - & - & - & - \\
\hline Poor self-esteem & 11 & $3 / 6$ & - & - & - & - \\
\hline Somatic complaints & 16 & $9 / 11$ & 1 & 3 & 3 & 7 \\
\hline \multicolumn{7}{|l|}{ Mental illness } \\
\hline Neurotic & 3 & $2 / 2$ & 0 & 2 & 2 & 4 \\
\hline Other & 12 & $6 / 7$ & 0 & 4 & 2 & 6 \\
\hline \multicolumn{7}{|l|}{ Aggression } \\
\hline Aggressive antisocial & 15 & $10 / 11$ & 0 & 1 & 6 & 7 \\
\hline Cruel & 2 & $2 / 2$ & 0 & 1 & 0 & 1 \\
\hline Delinquent & 7 & $6 / 6$ & 0 & 1 & 3 & 4 \\
\hline \multicolumn{7}{|l|}{ Sexualized behavior } \\
\hline \multicolumn{7}{|l|}{ Inappropriate sexual } \\
\hline behavior & 23 & $8 / 8$ & 6 & 2 & 0 & 8 \\
\hline Promiscuity & 2 & - & - & - & - & - \\
\hline School/learning problems & 13 & $5 / 6$ & 0 & 1 & 2 & 3 \\
\hline \multicolumn{7}{|l|}{ Behavior problems } \\
\hline Hyperactivity & 9 & $5 / 7$ & 0 & 1 & 4 & 5 \\
\hline Regression/immaturity & 7 & $2 / 2$ & 1 & 0 & 1 & 2 \\
\hline Illegal acts & 4 & - & - & - & - & - \\
\hline Running away & 6 & $1 / 1$ & - & - & - & - \\
\hline General & 5 & $2 / 2$ & - & - & - & - \\
\hline \multicolumn{7}{|l|}{ Self-destructive behavior } \\
\hline Substance abuse & 5 & 一 & - & - & - & - \\
\hline Self-injurious behavior & 4 & $1 / 1$ & - & - & - & 一 \\
\hline \multicolumn{7}{|l|}{ Composite symptoms } \\
\hline Internalizing & 10 & $8 / 8$ & 0 & 2 & 1 & 3 \\
\hline Externalizing & 11 & $7 / 7$ & 0 & $i$ & 2 & 3 \\
\hline
\end{tabular}

Note. The numbers in column 2 do not necessarily add up to the number in column 1 because column 1 includes some studies in which only the percentage of children with symptoms was specified.

${ }^{a}$ SA $>$ NSA = SA children were more symptomatic than NSA children. ${ }^{b}$ SA $<$ NSA $=$ SA children were less symptomatic than NSA children.

ple box score approach we used. Unfortunately, most of the studies we reviewed did not present data in a form amenable to the calculation of effect sizes. We were, however, able to calculate effect sizes (Table 2) for seven symptoms on which enough studies had provided adequate information for a comparison of abused and nonabused nonclinical children (all betweengroups comparisons ${ }^{4}$ ). The symptoms were anxiety, sexualized behavior, depression, withdrawal, aggression, internalizing, and externalizing.

Table 2 shows that sexual abuse status alone accounted for a very large percentage of the variance for all seven symptoms, with the sexually abused children manifesting significantly more of all these symptoms. The highest effect sizes (etas) were for the acting-out behaviors, such as sexualized behaviors and aggression. Sexual abuse status accounted for $43 \%$ of the variance for these two behaviors and $32 \%$ of the variance for externalizing. Such a large effect size is less surprising for sexualized behavior than it is for more global symptoms such as aggression and externalizing, which could have a variety of underlying causes.

Sexual abuse status also accounted for a large percentage of the variance $(35-38 \%)$ for the internalizing behaviors-internal-

\footnotetext{
${ }^{4}$ The criteria for including a study in this review were as follows: The authors reported an exact $t$ value or an $F$ value from a univariate analysis of variance, they reported the degrees of freedom, and there was only one degree of freedom in the numerator. Eta allowed us to examine the effects of sexual abuse apart from sample size and therefore provided a standard coefficient by which to compare findings (Rosenthal, 1984). In addition, because eta is comparable to a Pearson $r$, it provided an index of the strength of the relationship between sexual abuse status and manifestation of a symptom. Eta squared indicated how much of the variance was accounted for by the child's sexual abuse status. One needs to be cautious when interpreting results based on a small number of studies and widely ranging effect sizes. Unfortunately, very few investigators have reported results that are amenable to effect size calculations.
} 
Table 2

Average Effect Sizes for Seven Symptoms of Sexual Abuse

\begin{tabular}{lcccc}
\hline & \multicolumn{4}{c}{ Effect sizes } \\
\cline { 2 - 5 } \multicolumn{1}{c}{ Symptom } & $\begin{array}{c}\text { No. } \\
\text { studies }\end{array}$ & $\begin{array}{c}\text { Range of } \\
\eta^{2}\end{array}$ & $\begin{array}{c}\text { Average } \\
\eta\end{array}$ & $\begin{array}{c}\text { Average } \\
\eta^{2}\end{array}$ \\
\hline Aggression & 4 & $.37-.71$ & .66 & .43 \\
Anxiety & 3 & $.01-.28$ & .39 & .15 \\
Depression & 6 & $.06-.68$ & .59 & .35 \\
Externalizing & 5 & $.08-.52$ & .57 & .32 \\
Internalizing & 6 & $.11-.70$ & .62 & .38 \\
Sexualized & & & & .43 \\
$\quad$ behavior & 5 & $1.9-.77$ & .66 & .43 \\
Withdrawal & 6 & $.12-.68$ & .60 & .36 \\
\hline
\end{tabular}

izing, depression, and withdrawal. The smallest percentage of variance accounted for was for anxiety (15\%) but even this is a large effect.

Overall, the results of effect size analysis support the conclusion drawn from Table 1 that being sexually abused was strongly related to some symptoms specific to sexual abuse, such as sexualized behavior, as well as a range of more global symptoms such as depression, aggression, and withdrawal. Nonetheless, sexually abused children did not appear to be more symptomatic than were other clinical children, except in the case of PTSD and sexualized behavior.

\section{Percentages of Victims With Symptoms}

Many researchers simply reported whether sexually abused children were more symptomatic than nonabused children. Yet it is also important to know the actual percentage of victims with each symptom. Some symptoms may occur more often in sexually abused than nonabused children but occur so rarely that they are of little concern for the majority of children in treatment. The actual frequency of such symptoms in the population of abused children can be an important guide to clinicians in diagnosis and treatment. Furthermore, this information is helpful for clinicians and researchers who may want to anticipate the consequences of abuse or develop theory about the process of recovery from abuse. In Table 3, we synthesize information about these frequencies.

The range of children with each symptom varied widely from study to study, which is not unusual given the heterogeneity of sources. Therefore, for each symptom we calculated a weighted average across all studies, dividing the total number of children with a symptom by the total number of children in all the studies reporting on that symptom.

Across all studies, the percentage of victims with a particular symptom was mostly between $20 \%$ and $30 \%$. It is important to note that, with the exception of PTSD, no symptom was manifested by a majority of victims. However, there have been relatively few studies of PTSD, and half the children included in this calculation were victims of severe ritualistic abuse from Los Angeles-area day-care cases (Kelly, in press-a), thus inflating the percentage. If we exempt these unusually severely abused children, the average percentage of victims with symptoms of PTSD was $32 \%$, near the level of other frequently occurring symptoms such as poor self-esteem (35\%), promiscuity
(38\%), and general behavior problems (37\%). Because the Child Behavior Checklist (CBCL; Achenbach \& Edelbrock, 1984) was used in a large number of studies, we also calculated the percentage of children in the clinical range (or with "elevated scores") for internalizing and externalizing symptomatology.

Overall, the percentage of victims with the various symptoms may seem low to those with a clinical perspective. Part of the problem with the analysis of these composite percentages was that many of the symptoms did not occur uniformly across all age groups. We therefore reexamined the weighted percentages presented in Table 3, grouped by the age of the child at assessment. Percentages were calculated for preschool-age (approximately 0-6 years), school-age (approximately $7-12$ years), adolescent (approximately 13-18 years), and mixed age (e.g., 3-17 years) groups. The ages reported in different studies varied and overlapped a bit from these guidelines but by and large fell within these ranges. From a developmental standpoint, we should emphasize that these were very crude cuts across large developmental periods. Furthermore, they represented age at the time of report, not at the onset or end of molestation. In addition, there was no control for the context in which the abuse occurred or the variables that mediated the effects of that abuse.

The results of this analysis (Table 4) hint at possible developmental patterns. Differentiating the samples on the basis of major age groups appeared to yield more focused and consistent findings than when age groups were mixed.

For preschoolers, the most common symptoms were anxiety, nightmares, general PTSD, internalizing, externalizing, and inappropriate sexual behavior. For school-age children, the most common symptoms included fear, neurotic and general mental illness, aggression, nightmares, school problems, hyperactivity, and regressive behavior. For adolescents, the most common behaviors were depression; withdrawn, suicidal, or self-injurious behaviors; somatic complaints; illegal acts; running away; and substance abuse. Among the symptoms that appeared prominently for more than one age group were nightmares, depression, withdrawn behavior, neurotic mental illness, aggression, and regressive behavior.

To date, the majority of data on the effects of sexual abuse on children have been collected cross-sectionally, with data obtained only once per child. Nevertheless, from this cross-sectional data it is possible to hypothesize some developmental trajectories of changes in symptomatology. The question remains, however, as to whether these changes in symptomatology occur within a given child at different stages or represent developmental changes in response to sexual abuse at the time of report.

Depression appeared to be a particularly robust symptom across age groups and was also one that appeared frequently in adults molested as children, as two recent reviews have indicated (Beitchman et al., 1992; McGrath, Keita, Strickland, \& Russo, 1990). School and learning problems were also fairly prominent in all three age groups, especially school-age children and adolescents. This is a symptom that would not appear in adults but could be parallel to employment difficulties in adults, because both are structured environments to which the person must report every day and both require equivalent types of skills.

Behavior labeled as antisocial in preschool- and school-age 
Table 3

Percentage of Sexually Abused Children With Symptoms

\begin{tabular}{|c|c|c|c|c|}
\hline Symptom & $\begin{array}{l}\% \text { with } \\
\text { symptom }\end{array}$ & Range of $\% s$ & $\begin{array}{l}\text { No. } \\
\text { studies }\end{array}$ & $N$ \\
\hline Anxiety & 28 & $14-68$ & 8 & 688 \\
\hline Fear & 33 & $13-45$ & 5 & 477 \\
\hline \multicolumn{5}{|l|}{ Posttraumatic stress disorder } \\
\hline Nightmares & 31 & $18-68$ & 5 & 605 \\
\hline General & 53 & $20-77$ & 4 & 151 \\
\hline \multicolumn{5}{|l|}{ Depression } \\
\hline Depressed & 28 & $19-52$ & 6 & 753 \\
\hline Withdrawn & 22 & $4-52$ & 5 & 660 \\
\hline Suicidal & 12 & $0-45$ & 6 & 606 \\
\hline Poor self-esteem & 35 & $4-76$ & 5 & 483 \\
\hline Somatic complaints & 14 & $0-60$ & 6 & 540 \\
\hline \multicolumn{5}{|l|}{ Mental illness } \\
\hline Neurotic & 30 & $20-38$ & 3 & 113 \\
\hline Other & 6 & $0-19$ & 3 & 533 \\
\hline \multicolumn{5}{|l|}{ Aggression } \\
\hline Aggressive/antisocial & 21 & $13-50$ & 7 & 658 \\
\hline Delinquent & 8 & 8 & 1 & 25 \\
\hline \multicolumn{5}{|l|}{ Sexualized behavior } \\
\hline Inappropriate sexual behavior & 28 & $7-90$ & 13 & 1,353 \\
\hline Promiscuity & 38 & $35-48$ & 2 & 128 \\
\hline School/learning problems & 18 & $4-32$ & 9 & 652 \\
\hline \multicolumn{5}{|l|}{ Behavior problems } \\
\hline Hyperactivity & 17 & $4-28$ & 2 & 133 \\
\hline Regression/immaturity & 23 & $14-44$ & 5 & 626 \\
\hline Illegal acts & 11 & $8-27$ & 4 & 570 \\
\hline Running away & 15 & $2-63$ & 6 & 641 \\
\hline General & 37 & $28-62$ & 2 & 66 \\
\hline \multicolumn{5}{|l|}{ Self-destructive behavior } \\
\hline Substance abuse & 11 & $2-46$ & 5 & 786 \\
\hline Self-injurious behavior & 15 & $1-71$ & 3 & 524 \\
\hline \multicolumn{5}{|l|}{ Composite symptoms } \\
\hline Internalizing & 30 & $4-48$ & 3 & 295 \\
\hline Externalizing & 23 & $6-38$ & 3 & 295 \\
\hline
\end{tabular}

children might be labeled as illegal in adolescents. Similarly, the results of our analysis and a recent review by Beitchman et al. (1991) indicate that sexualized behaviors may be prominent for preschool-age children, submerge during latency (or the school-age period), and reemerge during adolescence as promiscuity, prostitution, or sexual aggression. These same symptoms might manifest themselves as sexual dysfunctions or sex offending in adulthood, although this has yet to be demonstrated empirically.

The results presented in Table 4 suggest that much symptomatology is developmentally specific and that generalizing across large age groups distorts the patterns. Fortunately, this is more a problem of data analysis and presentation of findings than it is of data collection, so future research should be able to address this issue. Developmental theory and suggestions for future research are described in the Discussion section.

\section{Percentages of Asymptomatic Victims}

In addition to the percentage of children with specific symptoms, another important statistic is the percentage of children with no symptoms. This figure has important clinical implications for the group of children in whom the impact of abuse may be muted or masked. Unfortunately, few investigators have reported on such asymptomatic children, perhaps out of concern that such figures might be misinterpreted or misused.

Nonetheless, when investigators have made such estimates, they have found a substantial, and perhaps to some surprising, proportion of the victims to be free of the symptoms being measured. For example, Caffaro-Rouget, Lang, and vanSanten (1989) found that $49 \%$ were asymptomatic at their assessment during a pediatric examination. Mannarino and Cohen (1986) found that $31 \%$ were symptom free, and Tong, Oates, and McDowell (1987) found that 36\% were within the normal range on the CBCL. Finally, Conte and Schuerman (1987b) indicated that $21 \%$ of their large sample appeared to have had no symptoms at all, even though their assessment included both very specific and broad items such as "fearful of abuse stimuli" and "emotional upset."

There are several possible explanations why so many children appeared to be asymptomatic. The first possibility is that the studies did not include measures of all appropriate symptoms or the researchers were not using sensitive enough instruments. In most individual studies, only a limited range of possible effects were examined. Thus some of the asymptomatic children may have been symptomatic on dimensions that were not being measured.

Another possibility is that asymptomatic children are those 
Table 4

Percentage of Children With Symptoms by Age Group

\begin{tabular}{|c|c|c|c|c|}
\hline \multirow[b]{2}{*}{ Symptom } & \multicolumn{4}{|c|}{$\begin{array}{c}\% \text { of subjects } \\
\text { (No. studies/No. subjects) }\end{array}$} \\
\hline & Preschool & School & Adolescent & Mixed \\
\hline Anxiety & $\begin{array}{c}61 \\
(3 / 149)\end{array}$ & $\begin{array}{c}23 \\
(2 / 66)\end{array}$ & $\begin{array}{r}8 \\
(1 / 3)\end{array}$ & $\begin{array}{c}18 \\
(4 / 470)\end{array}$ \\
\hline Fear & $\begin{array}{c}13 \\
(1 / 30)\end{array}$ & $\begin{array}{c}45 \\
(1 / 58)\end{array}$ & - & $\begin{array}{c}31 \\
(2 / 389)\end{array}$ \\
\hline \multicolumn{5}{|l|}{ Posttraumatic stress disorder } \\
\hline $\begin{array}{l}\text { Nightmares } \\
\text { General }\end{array}$ & $\begin{array}{c}55 \\
(3 / 183) \\
77 \\
(1 / 71)\end{array}$ & $\begin{array}{c}47 \\
(1 / 17) \\
-\end{array}$ & $\begin{array}{r}0 \\
(1 / 3) \\
-\end{array}$ & $\begin{array}{c}19 \\
(2 / 402) \\
32 \\
(3 / 80)\end{array}$ \\
\hline \multicolumn{5}{|l|}{ Depression } \\
\hline Depressed & $\begin{array}{c}33 \\
(3 / 149)\end{array}$ & $\begin{array}{c}31 \\
(2 / 66)\end{array}$ & $\begin{array}{c}46 \\
(3 / 129)\end{array}$ & $\begin{array}{c}18 \\
(2 / 409)\end{array}$ \\
\hline Withdrawn & $\begin{array}{c}10 \\
(1 / 30)\end{array}$ & $\begin{array}{c}36 \\
(1 / 58)\end{array}$ & $\begin{array}{c}45 \\
(2 / 126)\end{array}$ & $\begin{array}{c}15 \\
(3 / 446)\end{array}$ \\
\hline Suicidal & $\begin{array}{c}0 \\
(1 / 37)\end{array}$ & - & $\begin{array}{c}41 \\
(3 / 172)\end{array}$ & $\begin{array}{c}3 \\
(2 / 397)\end{array}$ \\
\hline Poor self-esteem & $\begin{array}{c}0 \\
(1 / 25)\end{array}$ & $\begin{array}{c}6 \\
(1 / 17)\end{array}$ & $\begin{array}{r}33 \\
(1 / 3)\end{array}$ & $\begin{array}{c}38 \\
(4 / 438)\end{array}$ \\
\hline Somatic complaints & $\begin{array}{c}13 \\
(2 / 54)\end{array}$ & - & $\begin{array}{c}34 \\
(1 / 44)\end{array}$ & $\begin{array}{c}12 \\
(2 / 442)\end{array}$ \\
\hline \multicolumn{5}{|l|}{ Mental illness } \\
\hline Neurotic & $\begin{array}{c}20 \\
(1 / 30)\end{array}$ & $\begin{array}{c}38 \\
(1 / 58)\end{array}$ & $\begin{array}{c}24 \\
(1 / 25)\end{array}$ & - \\
\hline Other & $\begin{array}{c}0 \\
(1 / 37)\end{array}$ & $\begin{array}{c}19 \\
(1 / 58)\end{array}$ & $\begin{array}{c}16 \\
(2 / 69)\end{array}$ & $\begin{array}{c}3 \\
(1 / 369)\end{array}$ \\
\hline \multicolumn{5}{|l|}{ Aggression } \\
\hline Aggressive/antisocial & $\begin{array}{c}27 \\
(3 / 154)\end{array}$ & $\begin{array}{c}45 \\
(1 / 58)\end{array}$ & - & $\begin{array}{c}14 \\
(3 / 446)\end{array}$ \\
\hline Delinquent & - & - & $\begin{array}{c}8 \\
(1 / 25)\end{array}$ & - \\
\hline \multicolumn{5}{|l|}{ Sexualized behavior } \\
\hline Inappropriate sexual behavior & $\begin{array}{c}35 \\
(6 / 334)\end{array}$ & $\begin{array}{c}6 \\
(1 / 17)\end{array}$ & $\begin{array}{r}0 \\
(1 / 3)\end{array}$ & $\begin{array}{c}24 \\
(7 / 999)\end{array}$ \\
\hline Promiscuity & - & - & $\begin{array}{c}38 \\
(2 / 128)\end{array}$ & - \\
\hline School/learning problems & $\begin{array}{c}19 \\
(2 / 107)\end{array}$ & $\begin{array}{c}31 \\
(1 / 58)\end{array}$ & $\begin{array}{c}23 \\
(2 / 69)\end{array}$ & $\begin{array}{c}17 \\
(2 / 418)\end{array}$ \\
\hline \multicolumn{5}{|l|}{ Behavior problems } \\
\hline Hyperactivity & $\begin{array}{c}9 \\
(2 / 55)\end{array}$ & $\begin{array}{c}23 \\
(2 / 75)\end{array}$ & $\begin{array}{r}0 \\
(1 / 3)\end{array}$ & - \\
\hline Regression/immaturity & $\begin{array}{c}36 \\
(4 / 159)\end{array}$ & $\begin{array}{c}39 \\
(2 / 75)\end{array}$ & $\begin{array}{r}0 \\
(1 / 3)\end{array}$ & $\begin{array}{c}15 \\
(2 / 389)\end{array}$ \\
\hline Illegal acts & - & - & $\begin{array}{c}27 \\
(1 / 101)\end{array}$ & $\begin{array}{c}8 \\
(3 / 469)\end{array}$ \\
\hline Running away & - & - & $\begin{array}{c}45 \\
(3 / 172)\end{array}$ & $\begin{array}{c}4 \\
(3 / 469)\end{array}$ \\
\hline General & $\begin{array}{c}62 \\
(1 / 17)\end{array}$ & - & - & $\begin{array}{c}28 \\
(1 / 49)\end{array}$ \\
\hline \multicolumn{5}{|l|}{ Self-destructive behavior } \\
\hline Substance abuse & - & - & $\begin{array}{c}53 \\
(2 / 128)\end{array}$ & $\begin{array}{c}2 \\
(3 / 658)\end{array}$ \\
\hline Self-injurious behavior & - & - & $\begin{array}{c}71 \\
(2 / 128)\end{array}$ & $\begin{array}{c}1 \\
(1 / 369)\end{array}$ \\
\hline \multicolumn{5}{|l|}{ Composite symptoms } \\
\hline Internalizing & $\begin{array}{c}48 \\
(1 / 69)\end{array}$ & - & - & $\begin{array}{c}24 \\
(2 / 226)\end{array}$ \\
\hline Externalizing & $\begin{array}{c}38 \\
(1 / 69)\end{array}$ & - & - & $\begin{array}{c}23 \\
(2 / 226)\end{array}$ \\
\hline
\end{tabular}


who have yet to manifest their symptoms. This could be either because the children are effective at suppressing symptoms or have not yet processed their experiences or because true traumatization occurs at subsequent developmental stages, when the children's victim status comes to have more meaning or consequences for them (Berliner, 1991). We would expect these children to manifest symptoms later on. In one study that supports this interpretation (Gomes-Schwartz, Horowitz, Cardarelli, \& Sauzier, 1990), the asymptomatic children were the ones most likely to worsen by the time of the 18-month follow up: $30 \%$ of them developed symptoms. To date, no one has replicated this finding, however.

A final explanation is that perhaps asymptomatic children are truly less affected. Research indeed suggests there is a relationship between the seriousness and duration of the abuse and the amount of impact (see Intervening Variables section, below). The asymptomatic children might be those with the least damaging abuse. They may also be the most resilient children, the ones with the most psychological, social, and treatment resources to cope with the abuse.

In fact, all three explanations may be simultaneously correct. Unfortunately, the issue of asymptomatic children has been peripheral until recently. Too few researchers have even mentioned the issue, and fewer still have looked at the correlates of being symptom free. Future studies need to address this issue more fully, not as a sidebar of unusual findings, but as a central topic in its own right.

\section{Intervening Variables}

In many studies ( 25 of the 46 we reviewed), researchers have tried to account for variations in the children's symptomatology by examining characteristics of the abuse experience. The results for variables with consistent findings are listed in Table 5. Variables with contradictory or confusing results are discussed in this section.

Age at the time of assessment has been the most commonly considered intervening variable. The majority of studies indicated that children who were older at the time of assessment appeared to be more symptomatic than those who were younger. However, most of these studies did not control for the effect of duration (those who were older may have had longer molestations), identity of the perpetrator (intrafamilial perpetrators may have been able to continue the abuse for a longer time), or severity of the molestation (older victims may have experienced more severe sexual acts). In three studies, no significant differences related to age at time of assessment were found (Einbender \& Friedrich, 1989; Friedrich, Urquiza, \& Beilke, 1986; Kolko, Moser, \& Weldy, 1988); in one study, younger children were more symptomatic (Wolfe, Gentile, \& Wolfe, 1989); and in one study there was a curvilinear relationship between age and symptomatology, with the middle age range being more symptomatic (Gomes-Schwartz, Horowitz, \& Sauzier, 1985). Although the data appear to indicate roughly that older children are more negatively affected, these results should be interpreted with caution because of the lack of control over other relevant variables.

Age of onset is another possible intervening variable. However, age of onset was related to symptoms in only one study, which showed that those with early age of onset were more likely to manifest symptoms of pathology (Zivney, Nash, \& Hulsey, 1988). In two other studies no difference was found in level of pathology for early versus late age of onset. By and large, it appears that age of onset must be fit into a total conceptual model of molestation. Research is insufficient to permit any conclusions about whether early versus late age of onset is more likely to lead to greater symptomatology. Age of onset might be related more to other characteristics of the abuse (such as identity of the perpetrator) than to overall number and severity of symptoms. Although the relationship of age of onset to symptomatology in children is not clear at this time, in two recent studies an early age of onset was found to be related to amnesia among adult survivors (Briere \& Conte, 1989) and late presentation for treatment (Kendall-Tackett, 1991).

With regard to sex of the subject, consistent differences in the reaction of boys and girls to molestation have been found in only a few studies. The scarcity of these findings is in sharp contrast to the popular belief that boys are likely to manifest externalizing symptoms and girls are more likely to exhibit internalizing symptoms. The absence of consistent gender differences is all the more interesting because girls are more likely to suffer intrafamilial abuse, which has been associated with more severe effects (Finkelhor, Hotaling, Lewis, \& Smith, 1990). The lack of more systematic attention to gender differences may be due in part to the small number of male victims in most studies and the possibility that, because of bias in the identification of male victims, only the most symptomatic boys end up in clinical samples. It may also be due to the fact that comparison of boys and girls has produced too few interesting differences to motivate researchers to place it in center focus. Nevertheless, researchers should address the issue of sex of the victims in future reports.

Penetration (oral, anal, or vaginal) did influence the impact of sexual abuse in the majority of studies, but most researchers differed in their definitions of severity of abuse. To further add to the confusion, some of the investigators added together all the sexual acts that a victim experienced, and therefore their indices of severity included the severity as well as the number of sexual acts. Even with all these variations, it appeared that molestations that contained some form of penetration were more likely to produce symptoms than molestations that did not.

The identity of the perpetrator is another factor that has been related to the impact of abuse. The weight of the evidence indicated that a perpetrator who was close to the victim caused more serious effects than one who was less close. To date there does not appear to be a uniform coding scheme for closeness, however. For example, fathers and stepfathers are often coded in the same category. Researchers should try to determine a measure of emotional closeness or degree of caretaking responsibility rather than relying on the kinship label of the perpetrator-victim relationship.

On a similar note, the impact of the number of perpetrators is not clear. The number of perpetrators was positively correlated with number of symptoms in one study, negatively correlated with number of symptoms in another, and not correlated with symptoms in another. Future research should address this issue.

Time elapsed since the last abusive incident and assessment is a variable with intuitive appeal, but it has been examined in 
Table 5

Influence of Intervening Variables

\begin{tabular}{|c|c|c|c|}
\hline \multirow[b]{2}{*}{ Variable } & \multicolumn{2}{|l|}{ No. studies } & \multirow[b]{2}{*}{ Direction of findings } \\
\hline & $\begin{array}{l}\text { With significant } \\
\text { difference in impact }\end{array}$ & Total & \\
\hline \multicolumn{4}{|l|}{ Age of child } \\
\hline At assessment & 7 & 10 & $\begin{array}{l}\text { Older children were more symptomatic } \\
\text { in five studies. }\end{array}$ \\
\hline At onset & 1 & 3 & Not clear. \\
\hline Sex of child & 5 & 8 & $\begin{array}{l}\text { Patterns of symptoms differed for boys } \\
\text { and giris. }\end{array}$ \\
\hline Penetration/severity & 6 & 10 & $\begin{array}{l}\text { Oral, anal, or vaginal penetration was } \\
\text { related to increased symptoms. }\end{array}$ \\
\hline Frequency & 4 & 6 & $\begin{array}{l}\text { Higher frequency was related to } \\
\text { increased symptoms. }\end{array}$ \\
\hline Duration & 5 & 7 & $\begin{array}{l}\text { Longer duration was related to increased } \\
\text { symptoms. }\end{array}$ \\
\hline Perpetrator & 7 & 9 & $\begin{array}{l}\text { Symptoms were increased when } \\
\text { perpetrator had close relationship } \\
\text { with child. }\end{array}$ \\
\hline No. perpetrators & 1 & 3 & Not clear. \\
\hline Lack of maternal support & 3 & 3 & $\begin{array}{l}\text { Lack of support was related to increased } \\
\text { symptoms. }\end{array}$ \\
\hline Force & 5 & 6 & $\begin{array}{l}\text { Use of force was related to increased } \\
\text { symptoms. }\end{array}$ \\
\hline $\begin{array}{l}\text { Time elapsed since last } \\
\text { abusive incident }\end{array}$ & 1 & 3 & Not clear. \\
\hline $\begin{array}{l}\text { Child's attitudes and } \\
\text { coping style }\end{array}$ & 2 & 2 & $\begin{array}{l}\text { Negative outlook and coping style were } \\
\text { related to increased symptoms. }\end{array}$ \\
\hline
\end{tabular}

very few studies. Only $55 \%$ of the articles in the present review even mentioned time elapsed, and it varied from a few days to several years. In only three studies was the possible relationship between time elapsed and the impact of abuse examined. In one study (Friedrich et al., 1986), children became less symptomatic over time, whereas in two other studies (McLeer, Deblinger, Atkins, Foa, \& Ralphe, 1988; Wolfe et al., 1989) it made no difference. It appears to be too early to decide whether time elapsed is correlated with the number of symptoms. Therefore, we should find out more about this variable before we assume that it makes no difference.

In summary, the findings of the various studies reviewed indicated that molestations that included a close perpetrator; a high frequency of sexual contact; a long duration; the use of force; and sexual acts that included oral, anal, or vaginal penetration lead to a greater number of symptoms for victims. Similarly, as all the studies that included these variables indicated, the lack of maternal support at the time of disclosure and a victim's negative outlook or coping style also led to increased symptoms. The influence of age at the time of assessment, age at onset, number of perpetrators, and time elapsed between the end of abuse and assessment is still somewhat unclear at the present time and should be examined in future studies on the impact of intervening variables.

It should be kept in mind when interpreting these findings that certain intervening variables are highly correlated. For example, intrafamilial abuse normally occurs over a longer time period and involves more serious sexual activity (i.e., penetration). These natural confounds make it difficult to fully analyze the independent effects of intervening variables. Very few stud- ies have included more than one or two of these variables, and almost no one has statistically controlled for their effects.

\section{Longitudinal Studies}

Perhaps the most encouraging development in the field has been the appearance of longitudinal studies (Bentovim, vanElberg, \& Boston, 1988; Conte, 1991; Everson, Hunter, \& Runyan, 1991; Friedrich \& Reams, 1987; Gomes-Schwartz et al., 1990; Goodman et al., in press; Hewitt \& Friedrich, 1991; Mannarino, Cohen, Smith, \& Moore-Motily, 1991; Runyan, Everson, Edelson, Hunter, \& Coulter, 1988; Valliere, Bybee, \& Mowbray, 1988; Waterman, in press). Most of these studies have followed children for approximately 12-18 months, with a few ranging from 2 to 5 years (Bentovim et al., 1988; Waterman, in press). These studies allow a perspective on two important issues: (a) What is the course of symptomatology over time, and (b) what contributes to recovery?

The picture provided by the longitudinal studies is tentative, but some generalizations are possible. Overall, symptoms seemed to abate with time. The pattern of recovery was different for different symptoms, and some children actually appeared to worsen.

\section{Abatement of Symptoms}

Abatement of symptoms has been demonstrated in at least seven longitudinal studies covering all age groups (Bentovim et al., 1988; Conte, 1991; Gomes-Schwartz et al., 1990; Goodman et al., in press; Hewitt \& Friedrich, 1991; Mannarino et al., 1991; 
Runyan et al., 1988). For example, Gomes-Schwartz et al. (1990) noted substantial diminution of emotional distress in $55 \%$ of the victims (mixed age group) over 18 months. In Bentovim et al's (1988) study, social workers found improvement in the level of symptoms in $61 \%$ of the children. Hewitt and Friedrich (1991) noted that $65 \%$ of preschool-age children improved over a period of 1 year. About two thirds of even the ritualistically abused preschoolers, who were initially in the clinical range on the CBCL (Waterman, in press), had moved back into the normal range on follow-up.

Nonetheless, there was a sizable group-anywhere from $10 \%$ to $24 \%$ - of children who appeared to get worse (Bentovim et al., 1988 [10\%]; Gomes-Schwartz et al., 1990 [24\%]; Hewitt \& Friedrich, 1991 [18\%]; Runyan et al., 1988 [14\%]). Some of these were children who had none of the symptoms measured at the time of initial assessment (Gomes-Schwartz et al., 1990).

Some investigators also noted a pattern in which symptoms tended to abate. Gomes-Schwartz et al. (1990) found that signs of anxiety (e.g., sleep problems or fear of the offender) were most likely to disappear, whereas signs of aggressiveness (e.g., fighting with siblings) tended to persist or worsen. This was consistent with Mannarino et al.'s (1991) finding of a significant reduction over time in the internalizing but not the externalizing scales of the CBCL. Conversely, some symptoms may increase over time. For example, one symptom that may increase over time, at least for the under-12 group, is sexual preoccupations (Friedrich \& Reams, 1987; Gomes-Schwartz et al., 1990). It is not entirely clear what this symptom abatement implies. Although some symptoms may be more transient than others, it does not necessarily mean that underlying trauma is resolved, but perhaps only that overt manifestations are more easily masked. Moreover, these changes may have less to do with abatement of trauma than developmental changes in symptomatology, with children at each age manifesting different types of symptoms.

There is a long list of correlates of improvement over time, but few of these findings have been demonstrated in more than one study. Age was not found to be strongly correlated with recovery in any study, although Goodman et al. (in press) found that 6-11-year-olds recovered most quickly in the very short term (3 months after the trial). Neither gender (GomesSchwartz et al., 1990; Goodman et al., in press), nor race and socioeconomic status (Gomes-Schwartz et al., 1990) have been factors in recovery. Children who were the most disturbed at the time of first assessment were found to make the most recovery (Gomes-Schwartz et al., 1990), but this may have been an artifact.

\section{Family and Treatment Variables}

A key variable in recovery was family support, demonstrated by several studies. Children who had maternal support recovered more quickly (Everson et al., 1991; Goodman et al., in press). Maternal support was demonstrated through believing the child and acting in a protective way toward the child. Waterman (in press) found that the least symptomatic children ( 5 years after disclosure) were those whose mothers were most supportive and whose families had less strain, enmeshment, and expressions of anger.
Interestingly, the effect of long-term therapy has not been extensively examined. In one study (Gomes-Schwartz et al., 1990), all clients received crisis intervention through the research project. The clients who showed the greatest amount of recovery (15\% of subjects) were those who received therapy in the specialized program run by the research team. Those who received therapy in the community at large ( $20 \%$ of subjects) did not appear to recover as well. The authors did not elaborate on the type of long-term therapy that clients received either through the researchers' program or in the community at large, however. In contrast, Goodman et al. (in press) found psychological counseling unrelated to improvement. But again, clients sought therapy in the outside community and there was no control for the type or quality of the therapy they received.

\section{Court Involvement}

The impact of court involvement and testimony was also a focus of several of the longitudinal studies because of the intense public policy debate surrounding this issue. In one study (Goodman et al., in press), children involved in court proceedings were slower to recover over both a 7- and an 11-month period than children not involved in court. Recovery was particularly impeded among children who had to testify on multiple occasions, who were afraid of their perpetrators, and who testified in cases in which there was no other corroborating evidence. Whitcomb et al.'s (1991) findings echoed Goodman et al.'s. Whitcomb et al. concluded that there were adverse effects for older children who had to undergo numerous, lengthy, or harshly contested courtroom testimony. The outcome of the trial (conviction or acquittal of the perpetrator), or the number of times that the child was interviewed did not relate to symptomatology (Goodman et al., in press).

Runyan et al. (1988) had more mixed findings with regard to the impact of court involvement. The children who had slower recovery in this study were those who were involved in a criminal case that was still not resolved 5 months after the initial evaluation. However, children whose cases had terminated more quickly with a conviction or plea bargain recovered just as quickly as children who had no court involvement at all. In fact, children who testified in juvenile court proceedings recovered more quickly. However, in a follow-up of adolescents from the same study, Everson et al. (1991) found that having to testify on multiple occasions caused negative effects, concurring with the findings of Goodman et al. (in press).

Although the longitudinal studies showed the risks involved in testimony, at least one cross-sectional study (Williams, 1991) confirmed that testimony in protected court settings can mitigate trauma. In this study of victims abused in day care, children who testified via closed-circuit television or videotaped testimony or in closed courtrooms suffered fewer symptoms of maladjustment than did children who testified in open court.

Overall, this small number of studies suggests that criminal court involvement posed risks to children's recovery, at least in the short run. But the risks were specifically associated with certain aspects of court involvement that can be modified or avoided. For example, negative impact can be lessened by resolving cases quickly, by preventing a child from having to testify on multiple occasions, and by not requiring a frightened 
child to face a defendant. Thus, although the research urges caution, it cannot be interpreted as a categorical argument against the prosecution of sexual abuse.

\section{Revictimization}

Follow-up studies lend an important perspective to the question of whether abuse victims are reabused in the year or two after disclosure. Most of the follow-up studies we reviewed showed the rate of reabuse to be between $6 \%$ and $19 \%$ (Bentovim et al., 1988 [16\%]; Daro, 1988 [19\%]; Gomes-Schwartz et al., $1990[6 \%]$ ), with follow-up ranging from 18 months to 5 years. Daro (1988) pointed out that the reabuse rate for sexually abused children in her study was still substantially lower than the reabuse rate for victims of neglect or emotional abuse.

\section{Summary}

In summary, in the first year or year and a half after disclosure, one half to two thirds of all children became less symptomatic, whereas $10-24 \%$ become more so. Six to nineteen percent experienced additional sexual abuse. Fears and somatic symptoms abated the most quickly; aggressiveness and sexual preoccupations were the most likely to remain or increase. Children's recovery was clearly assisted by a supportive family environment, and certain kinds of court experiences delayed recovery.

\section{Discussion}

The present review confirms the general impression that the impact of sexual abuse is serious and can manifest itself in a wide variety of symptomatic and pathological behaviors. There is virtually no general domain of symptomatology that has not been associated with a history of sexual abuse. Age and a variety of abuse-related factors can affect both the nature and the severity of symptoms. However, some sexually abused children may also appear to have no apparent symptoms. Indeed, approximately one third of sexually abused children in the studies we reviewed fell into this category. These findings have a number of important implications for theory development.

\section{Core-Symptom Theories}

The first and perhaps most important implication is the apparent lack of evidence for a conspicuous syndrome in children who have been sexually abused. The evidence against such a syndrome includes the variety of symptoms children manifest and the absence of one particular symptom in a large majority of children. Despite the lack of a single symptom that occurs in the majority of victims, both sexualized behavior and symptoms of PTSD occurred with relatively high frequency. These also appeared to be the only two symptoms more common in sexually abused children than in other clinical groups. Even though they do not occur in all victims, some theorists have forwarded PTSD and sexualized behaviors as the core manifestations of sexual abuse trauma (Corwin, 1989; Jampole \& Weber, 1987; Wolfe et al., 1989), so the evidence pertaining to these two symptoms is worth reviewing more carefully.

The frequency of sexualized behavior in sexually abused children (including frequent and overt self-stimulation; inap- propriate sexual overtures toward other children and adults; and compulsive talk, play, and fantasy with sexual content) is somewhat difficult to determine. Although it is the most regularly studied symptom, its occurrence varies enormously. Across six studies of preschoolers (the children most likely to manifest such symptoms) an average of $35 \%$ exhibited sexualized behavior. Friedrich et al. (1992), using an instrument specially designed to measure such behaviors, detected a somewhat higher percentage. But across all sexually abused children it may be only half of all victims. The lowest estimate (7\%) was based on a very large study, including many well-functioning and older children (Conte \& Schuerman, 1987b). Besides sample and methodological differences, other variations may well arise because the concept itself can be vague (sometimes it is called inappropriate sexual behavior, and other times it is called sexual acting out). Furthermore, some forms of sexualization may be quite minor and transitory (e.g., playing with anatomical dolls), whereas others may be deeply etched, even affecting a child's physiology. Putnam (1990; F. Putnam, personal communication, January 10,1991 ) detected elevated hormone levels among some sexually abused girls and evidence that onset of puberty was advanced for these girls by as much as 1 year. Although such physiological changes could be the effect of sexualization or, alternatively, one of its sources, it suggests how profound and pervasive the impact of sexual abuse can be.

Although sexualization is relatively specific to sexual abuse (more so than symptoms such as depression), nonsexually abused children may also be sexualized. For example, Deblinger, McLeer, Atkins, Ralphe, and Foa (1989) found that $17 \%$ of physically (but not sexually) abused children exhibited sexually inappropriate behavior. Although sexualized behavior may be the most characteristic symptom of sexual abuse, and the one that best discriminates between abused and nonabused children, as many as half of victims may not be overtly sexualized, and this symptom does not occur only in sexually abused children. From a clinical point of view, this symptom may indicate sexual abuse but is not completely diagnostic because children can apparently appear to be sexualized for other reasons.

The evidence for PTSD as a central effect of sexual abuse is also its relative frequency (particularly in preschool- and school-age victims) and its higher incidence in sexual abuse victims than in other clinical groups. Although PTSD is relatively common in child sexual abuse victims, it is not a universal reaction. In the two most thorough clinical evaluations of PTSD (according to criteria in the revised third edition of the Diagnostic and Statistical Manual of Mental Disorders; American Psychiatric Association, 1987), 48\% (McLeer et al., 1988) and $21 \%$ (Deblinger et al., 1989) of sexually abused children could be diagnosed as having PTSD. Although many other children have related symptoms, such as fears, nightmares, somatic complaints, autonomic arousal, and guilt feelings, it is not clear whether this is evidence for PTSD dynamics or other symptoms. More importantly, PTSD is not specific to sexual abuse in that many nonsexually abused children suffer from PTSD.

PTSD has served as a focal point for the analysis of sexual abuse trauma in part because it is a well-developed, generalized theory of traumatic processes. Finkelhor (1987), however, has raised some questions about how well the model of PTSD accounts for sexual abuse trauma. Theorists describe PTSD as 
resulting from experiences that are overwhelming, sudden, and dangerous (Figley, 1986; Pynoos \& Eth, 1985). Much sexual abuse, however, lacks these components, especially abuse that occurs through manipulation of the child's affections and misrepresentation of social standards. Thus, although many children may suffer symptoms that are explained by the PTSD model, the theory and the empirical findings do not support PTSD symptomatology as universal to sexual abuse or as the most characteristic pattern.

There is at least one other core-symptom theory about the effect of sexual abuse, one that argues that the central damage is to children's self-image (Bagley \& Young, 1989; Putnam, 1990). According to this view, it is the damaged self-image, not the sexual abuse per se, that leads to other difficulties. If this theory were true, disturbed self-esteem should be one of the most consistent, pervasive, and long-lasting effects of sexual abuse. Unfortunately, although many victims do have low self-esteem, researchers (e.g., Mannarino et al., 1991) have had considerable difficulty demonstrating this phenomenon. It is not certain whether poor self-esteem, which has been assessed primarily through self-reports, has been effectively measured. But the evidence to date does little to support the theory that self-esteem is the core element of sexual abuse traumatization.

\section{Multifaceted Models of Traumatization}

Overall, the absence of one dominant and consistent set of symptoms argues against these core-domain theories. Rather, these data suggest that the impact of sexual abuse is more complicated because it produces multifaceted effects. Several conceptual models are consistent with such a pattern. Finkelhor and Browne's (1985) model suggests that sexual abuse traumatizes children through four distinctive types of mechanisms, which account for the variety of outcomes. The four mechanisms have been termed (a) traumatic sexualization, (b) betrayal, (c) stigmatization, and (d) powerlessness. Traumatic sexualization includes a variety of processes such as the inappropriate conditioning of the child's sexual responsiveness and the socialization of the child into faulty beliefs and assumptions about sexual behavior. Betrayal includes the shattering of the child's confidence that trusted persons are interested in and capable of protecting him or her from harm. Stigmatization covers all the mechanisms that undermine the child's positive self-image: the shame that is instilled, the ostracism the child suffers, and the negative stereotypes that are acquired from the culture and immediate environment. Finally, powerlessness comprises PTSD-type mechanisms (intense fear of death or injury from an uncontrollable event) as well as the repeated frustration of not being able to stop or escape from the noxious experience or elicit help from others. These mechanisms are present to varying degrees and in different forms in different abuse scenarios.

In addition, Finkelhor and Browne (1985) propose that certain symptoms are more closely related to certain dynamics. The sexualization symptoms have an obvious connection to the traumatic sexualization processes, self-esteem is connected to stigmatization, and fears and PTSD are connected to powerlessness. Little research has been carried out to confirm the model in part because of its complexity, the variety of different mechanisms posited, and the difficulty of clearly delineating and measuring them.

Other theorists have also adopted a multiple-dynamics approach to account for the seeming variety of sexual abuse symptoms. Briere (1992) has developed such a model whose dynamics include (a) negative self-evaluation, (b) chronic perception of danger or injustice, (c) powerlessness and preoccupation with control, (d) dissociative control over awareness, (e) impaired self-reference, and (f) reduction of painful internal states.

A different model posits sexual abuse as simply a generalized stressor. Although this model has not been specifically developed, it is another way to understand the impact of sexual abuse. In this model, the child is likely to develop problems in whatever area he or she may have had a prior vulnerability. This model predicts a high degree of similarity between the effects of sexual abuse and the effects of other childhood stressors such as parental divorce. There is some evidence to support this view, particularly our finding in the present review of similarity on some symptoms between sexually abused children and other clinical groups. On the other hand, sexually abused children do tend to exhibit some characteristics (e.g., sexualized behaviors) that are much more common among sexually abused children than they are among other clinical groups. These types of effects argue against sexual abuse as merely a generalized stressor.

A third model posits family dysfunction or a general maltreating environment, not the sexually abusive activities per se, as the root of the trauma in most sexually abused children (Clausen \& Crittenden, 1991). This model is supported by apparent similarities in the range and types of problems manifested by all abused children. However, certain evidence from the studies included in the present review argues against such a conceptualization. First, the studies showed that nonabused siblings (i.e., children raised in the same dysfunctional families) displayed fewer symptoms than did their abused siblings (Lipovsky, Saunders, \& Murphy, 1989). In addition, the review of the 25 studies in which the influence of intervening variables was examined (Table 5) consistently showed strong relationships between specific characteristics of the sexual abuse and the symptomatology in the children (e.g., Newberger, Gremy, \& Waternaux, 1990). All of this argues for traumatic processes inherent in the sexual abuse itself that are independent from a generalized family dysfunction or generalized maltreating environment.

This is not to say that prior vulnerabilities, a maltreating environment, and family dysfunction do not contribute to traumatization as well. Research such as Conte and Schuerman's (1987a, 1987b) demonstrates that both abuse-related factors and family dysfunction contribute to children's trauma. And Conte and Schuerman found that over time, the abuse-related factors were less influential than the continuing family processes, such as the amount of family support for the child. This suggests a grand model of sexual abuse trauma that includes effects that are both more and less specific to sexual abuse and that arise from the abusive acts in particular, which also interact with prior vulnerabilities of the child, the health or toxicity of the family environment, and the social response to the discovery of abuse. 


\section{Summary}

The research to date points to an array of traumatizing factors in sexual abuse, with sexualization and PTSD as frequent, but not universal, processes. The traumatic impact of the abusive acts themselves (e.g., their frequency and severity) has been established, as well as the likely contribution of other familial and environmental conditions. The role of disturbance to selfesteem and of a child's prior dispositions or vulnerabilities has not been as well substantiated.

This theoretical discussion has implications for clinicians as well as researchers. The range of symptoms, the lack of a single predominant symptom pattern, and the absence of symptoms in so many victims clearly suggest that diagnosis is complex. Because the effects of abuse can manifest themselves in too many ways, symptoms cannot be easily used, without other evidence, to confirm the presence of sexual abuse. Yet the absence of symptoms certainly cannot be used to rule out sexual abuse. There are too many sexually abused children who are apparently asymptomatic. This finding is especially important for those conducting forensic evaluations.

It may be possible, as Corwin (1989) has argued, to find a combination of symptoms that is extremely diagnostic of sexual abuse, especially in certain subgroups of victims (e.g., preschool children with certain kinds of sexualized behavior and posttraumatic play), and research toward such a screening device may be warranted. But the evidence suggests that such a device would identify only a small percentage of victims and that one could conclude nothing at all from the absence of such symptom patterns.

Although conclusions such as these are useful, we also think this discussion highlights a glaring inadequacy in the literature: a nearly universal absence of theoretical underpinnings in the studies being conducted on this subject to date. Researchers evince a great deal of concern about the effects of sexual abuse but disappointingly little concern about why the effects occur. Few studies are undertaken to establish or confirm any theory or explanation about what causes children to be symptomatic. Rather, most researchers simply document and count the existence of symptoms and some of their obvious correlates. This accounts for one of the main reasons that, in spite of numerous studies since Browne and Finkelhor's (1986) review, there have been few theoretical advances.

Future studies need to turn to the development and confirmation of theory. Those who believe that different mechanisms result in different symptoms need to begin to search for such mechanisms. For example, if dissociation is theorized as an acquired strategy for escaping from unpleasant emotions, then researchers need to document the presence of the cognitive, affective, and physiological underpinnings to this mechanism and relate it to the trauma itself. By contrast, those who see sexual abuse as a generalized stressor need to conduct studies that relate the effects of sexual abuse to preexisting vulnerabilities in coping. The dialogue about variables that mediate the effects of abuse needs to be expanded and ideas forwarded about how to study and test their existence. This process of improving research might be assisted when the sexual abuse researchers join forces with those who study related symptomatology in nonabused children. This has already happened in the work generated by the importation of PTSD theory into the field, and it is only by further developing this cross-fertilization that advances can continue.

\section{Methodological Issues and Directions for Future Research}

Although the studies we reviewed signal an enormous improvement in methodology, they highlight many major areas where current designs could be improved or refined. Some more specific suggestions for improvement are offered in this section.

\section{Improvement in Measures of Impact}

The literature on effects has relied extensively on parentcompleted checklists of children's symptomatology, particularly the CBCL. However, two sets of findings have raised concern about the validity of these measures. One shows that mothers' judgments about their children's symptoms are highly related to their own level of distress and willingness to believe their children (Everson, Hunter, Runyan, Edelsohn, \& Coulter 1989; Newberger et al., 1990). A second shows a poor association between parents' and children's own reports (Cohen \& Mannarino, 1988; Kelly \& Ben-Meir, in press).

It does seem plausible that parents might be biased reporters, especially in the context of a family problem like sexual abuse, where parents can experience strong feelings of guilt or ambivalence about a child's disclosure. But other findings suggest that parent reports are nonetheless relatively valid and, in the context of currently used instruments, probably better than their children's reports. For example, although depressed mothers reported more child symptoms than nondepressed mothers on the CBCL, the assessments still differentiated disturbed and nondisturbed children when depression was statistically controlled (Friedlander, Weiss, \& Taylor, 1986). Moreover, mothers' ratings tended to be more similar to and correlated better with therapists' and teachers' ratings than with those of their children (Shapiro, Leifer, Martone, \& Kassem, 1990; Tong et al., 1987). It appears from several studies (Cohen \& Mannarino, 1988; Shapiro et al., 1990) that children's self-reports minimize problems like depression or low self-esteem that are noted by parents and therapists. Why this is so is not clear.

One clear implication from this is that researchers should not rely on children's self-reports alone. Ideally, assessments should be obtained from multiple sources, as Waterman, Kelly, McCord, and Oliveri (in press) recently did. In addition, research needs to be undertaken to improve the validity of parent reports and especially, if possible, children's self-assessments.

A second concern, raised in part by the issue of seemingly asymptomatic children, is whether the instruments currently being used are sensitive enough to measure consistently and accurately the trauma of sexual abuse. Several groups of researchers, recognizing particularly the limitations of the CBCL, have branched out in attempts to develop such sensitive measures. Friedrich et al. (1992) have greatly expanded CBCL symptom items in the domain of sexuality. Lanktree and Briere (1991, 1992) have adapted the Trauma Symptom Checklist, highly successful in differentiating sexually abused adults, for 
use with children. Wolfe et al. (1989) have developed scales to measure more sensitively PTSD-type symptomatology. Such efforts need to be continued and elaborated.

\section{Greater Differentiation by Age and Gender}

Many researchers have studied subjects from very broad age ranges (e.g., 3-18 years) and grouped them together to discuss symptoms. Similarly, they have grouped boys and girls together. As shown in Table 4, this grouping together of all ages can mask particular developmental patterns of the occurrence of some symptoms. At a minimum, future researchers should divide children into preschool, school, and adolescent age ranges when reporting the percentages of victims with symptoms. It would be better to provide even more detail on how age at assessment affects the manifestation of symptoms, by looking at smaller age ranges and tying this information into theory about children's social, emotional, and cognitive development during these difficult developmental periods. A parallel effort is needed with regard to gender.

\section{Expanded Analysis of Intervening Variables}

The present review confirms that abuse-related variables are associated with outcome and thus should be regularly included in analyses. However, many other factors probably are influential as well, and more emphasis should be placed on understanding their role. These factors include children's intelligence, coping skills, prior adjustment, and cognitive interpretation of the abuse. It also includes children's family and social environment, as well as the actions taken by professionals in response to their disclosures. Another factor that needs to be regularly taken into account is time elapsed since the end of the abuse. In some samples, several years might have elapsed between the end of the abuse and the assessment of the child, and during this time symptoms may have abated.

\section{Longitudinal Research and Developmental Theory}

A developmental perspective is one approach that may encourage more theory-driven research. Researchers using a developmental approach may also respond to some of the methodological issues raised here. Current research has tended to focus on assessments of trauma at a specific age or point in time (a snapshot approach), but it would also be helpful to know more about the course of symptomatology and recovery over time. For example, the symptomatology of a 15 -year-old molested at age 4 may be different from that of a 15 -year-old molested at age 14. Furthermore, symptoms may tend to recur at different developmental stages and asymptomatic children may later become symptomatic. Studies in which data are collected at more than one time point will encourage this developmental approach for studying sexual abuse and may answer many of our questions (see Baltes, 1987; Starr, MacLean, \& Keating, 1991). Even in the absence of funding, any research on outcomes should at least pave the way for possible later follow-up by gaining permission to recontact subjects and by recording data that will facilitate such research in the future.

In addition to studying abuse at multiple time points, develop- mental research means incorporating the multiple dimensions of children's development. Changes occur in children's behaviors, thoughts, and emotions at every developmental stage. Research on the effects of sexual abuse on children tends to focus predominantly on behavioral and emotional symptoms while ignoring the effects of sexual abuse on cognitive and social development.

A number of research questions can be generated by examining sexual abuse within the multiple dimensions of children's development. For example, cognitive development could influence children's interpretations of sexual abuse and the symptoms they subsequently manifest. Specifically, as children mature, their thinking becomes less egocentric. This issue alone generates several possible research questions. For example, are young children more likely to see themselves as responsible for the abuse ("It happened because I was bad") than are less egocentric older children? Furthermore, are children who see themselves as responsible for the abuse more likely to engage in self-abusive or destructive behavior? How do internal attributions affect children's reactions to prosecution of the perpetrator? Are these attributions more likely to increase the children's sense of guilt when the perpetrator is punished?

Along these same lines, children's cognitive development can influence their emotional and social development and their interpretation of the perpetrators' actions. As thinking becomes decentered, children recognize that people can have both positive and negative traits and that they themselves can have both positive and negative feelings toward others. How does the gradual attainment of decentered thinking affect children's interpretations of the perpetrators' actions, their own behaviors, and the abuse itself? This is especially important to understand when the perpetrator is someone whom the child loves and trusts. Are children who can see conflicting traits in others more likely to report abuse because they see it as only one part of their relationship with the perpetrator ("I love him but I want the abuse to stop")?

These are but a few of the types of research questions that can be generated from examining abuse from a developmental and multidimensional perspective. Future researchers could make specific predictions based on developmental theory and clinical research on related topics (e.g., children's reactions to other types of childhood traumas). This type of framework would also allow researchers to incorporate information about intervening variables such as the timing and duration of the abuse and the identity of the perpetrator.

In summary, studies conducted with a developmental and multidimensional framework could readily incorporate the many intervening variables that modify the effects of abuse. In addition, such a framework offers a richer description of why children and adults manifest certain symptoms at each developmental stage and how people cope with psychic trauma. Developmental psychologists and child clinicians could collaborate to develop models of how children at each developmental stage might be affected by their abuse experience. Researchers studying child sexual abuse have looked in isolation at many of the factors related to the impact of abuse. Now it is time for us to combine them into more realistic models. Research of this type would provide helpful theoretical information about the mechanism and processing of psychological trauma in general. It 
would also provide guidelines on where clinicians can effectively intervene to aid children in their healing process.

\section{References}

Achenbach, T. M., \& Edelbrock, C. S. (1984). Child behavior checklist. Burlington VT: University of Vermont.

Adams-Tucker, C. (1982). Proximate effects of sexual abuse in childhood: A report on 28 children. American Journal of Psychiatry, 139, 1252-1256.

American Psychiatric Association. (1987). Diagnostic and statistical manual of mental disorders (3rd ed., rev). Washington, DC: Author.

Bagley, C., \& Young, L. (1989). Depression, self-esteem, and suicidal behavior as sequels of sexual abuse in childhood: Research and therapy. In M. Rothery \& G. Cameron (Eds.), Child maltreatment: Expanding our concept of healing (pp. 183-209). Hillsdale, NJ: Erlbaum.

Baltes, P. B. (1987). Theoretical propositions of live-span developmental psychology: On the dynamics between growth and decline. Developmental Psychology, 23, 611-626.

Basta, S. M., \& Peterson, R. F. (1990). Perpetrator statusand the personality characteristics of molested children. Child Abuse and Neglect, 14, 555-566.

Beitchman, J. H., Zucker, K. J., Hood, J. E., daCosta, G. A., \& Akman, D. (1991). A review of the short-term effects of child sexual abuse. Child Abuse and Neglect, 15, 537-556.

Beitchman, J. H., Zucker, K. J., Hood, J. E., daCosta, G. A., Akman, D., \& Cassavia, E. (1992). A review of the long-term effects of child sexual abuse. Child Abuse and Neglect, 16, 101-118.

Bentovim, A., vanElberg, A., \& Boston, P. (1988). The results of treatment. In A. Bentovim, A. Elton, J. Hildebrand, M. Tranter, \& E. Vizard (Eds.), Child sexual abuse within the family: Assessment and treatment (pp. 252-268). London: Wright.

Berliner, L. (1991). The effects of sexual abuse on children. Violence Update, $1,1-10$.

Briere, J. (1992). Child abuse trauma: Theory and treatment of the lasting effects. Newbury Park, CA: Sage.

Briere, J., \& Conte, J. (1989, August). Amnesia in adults molested as children: Testing theories of repression. Paper presented at the 97th Annual Convention of the American Psychological Association, New Orleans, LA.

Browne, A., \& Finkelhor, D. (1986). The impact of child sexual abuse: A review of the research. Psychological Bulletin, 99, 66-77.

Burgess, A., Hartman, C., McCausland, M., \& Powers, P. (1984). Response patterns in children and adolescents exploited through sex rings and pornography. American Journal of Psychiatry, 141, 656662.

Burns, N., Williams, L. M., \& Finkelhor, D. (1988). Victim impact. In D. Finkelhor, L. M. Williams, \& N. Burns (Eds.), Nursery crimes: Sexual abuse in daycare (pp. 114-137). Newbury Park, CA: Sage.

Caffaro-Rouget, A., Lang, R. A., \& vanSanten, V.(1989). The impact of child sexual abuse. Annals of Sex Research, 2, 29-47.

Clausen, A. H., \& Crittenden, P. M. (1991). Physical and psychological maltreatment: Relations among types of maltreatment. Child Abuse and Neglect, 15, 5-18.

Cohen, J. A., \& Mannarino, A. P. (1988). Psychological symptoms in sexually abused girls. Child Abuse and Neglect, 12, 571-577.

Conte, J. R. (1991), Behavior of sexually abused children at intake/disclosure and 12 months later. Unpublished manuscript.

Conte, J., \& Schuerman, J. (1987a). Factors associated with an increased impact of child sexual abuse. Child Abuse and Neglect, 11, 201-211.

Conte, J., \& Schuerman, J. (1987b). The effects of sexual abuse on chil- dren: A multidimensional view. Journal of Interpersonal Violence, 2 , 380-390.

Corwin, D. L. (1989). Early diagnosis of child sexual abuse: Diminishing the lasting effects. In G. E. Wyatt \& G. J. Powell (Eds.), Lasting effects of child sexual abuse (pp. 251-270). Newbury Park, CA: Sage.

Daro, D. (1988). Confronting child abuse: Research for effective program design. New York: Free Press.

Deblinger, E., McLeer, S. V., Atkins, M. S., Ralphe, D., \& Foa, E. (1989). Post-traumatic stress in sexually abused, physically abused, and nonabused children. Child Abuse and Neglect, 13, 403-408.

Einbender, A. J., \& Friedrich, W. N. (1989). Psychological functioning and behavior of sexually abused girls. Journal of Consulting and Clinical Psychology, 57, 155-157.

Elwell, M. E., \& Ephross, P. H. (1987). Initial reactions of sexually abused children. Social Casework, 68, 109-116.

Erickson, M. F. (1986, August). Young sexually abused children: Socioemotional development and family interaction. Paper presented at the 94th Annual Convention of the American Psychological Association, Washington, DC.

Everson, M. D., Hunter, W. M., \& Runyan, D. K. (1991, January). Adolescent adjustment after incest: Who fares poorly? Paper presented at the San Diego Conference on Responding to Child Maltreatment, San Diego, CA.

Everson, M. D., Hunter, W. M., Runyan, D. K., Edelsohn, G. A., \& Coulter, M. L. (1989). Maternal support following disclosure of incest. American Journal of Orthopsychiatry, 59, 197-207.

Feltman, R. I. (1985). A controlled correlational study of the psychological functioning of female paternal incest victims. Unpublished doctoral dissertation.

Figley, C. R. (1986). Trauma and its wake:Vol. II. Traumatic stress theory research, and intervention. New York: Brunner/Mazel.

Finkelhor, D. (1987). The trauma of child sexual abuse: Two models Journal of Interpersonal Violence, 2, 348-366.

Finkelhor, D., \& Browne, A. (1985). The traumatic impact of child sexual abuse: A conceptualization. American Journal of Orthopsychiatry, 55, 530-541.

Finkelhor, D., Hotaling, G., Lewis, I. A., \& Smith, C. (1990). Sexual abuse in a national study of adult men and women: Prevalence, characteristics, and risk factors. Child Abuse and Neglect, 14, 19-28.

Friedlander, S., Weiss, D. S., \& Taylor, J. (1986). Assessing the influence of maternal depression on the validity of the Child Behavior Checklist. Journal of Abnormal Child Psychology, 14, 123-133.

Friedrich, W., Beilke, R., \& Urquiza, A. (1987). Children from sexually abusive families: A behavioral comparison. Journal of Interpersonal Violence, 2, 391-402.

Friedrich, W. N., Beilke, R. L., \& Urquiza, A. J. (1988). Behavior problems in young sexually abused boys. Journal of Interpersonal Violence, 3, 21-28.

Friedrich, W. N., Grambasch, P., Damon, L., Hewitt, S. K., Koverola, C., Lang, R., \& Wolfe, V. (1992). The Child Sexual Behavior Inventory: Normative and clinical comparisons. Psychological Assessment, 4, 303-311.

Friedrich, W. N., \& Luecke, W. J. (1988). Young school-age sexually aggressive children. Professional Psychology: Research and Practice, 19, 155-164.

Friedrich, W. N., \& Reams, R. A. (1987). Course of psychological symptoms in sexually abused young children. Psychotherapy; 24, 160170.

Friedrich, W. N., Urquiza, A. J., \& Beilke, R. L. (1986). Behavior problems in sexually abused young children. Journal of Pediatric Psychology, 11, 47-57.

Gale, J., Thompson, R. J., Moran, T., \& Sack, W. H. (1988). Sexual abuse in young children; Its clinical presentation and characteristic patterns. Child Abuse and Neglect, 12, 163-170. 
Gomes-Schwartz, B., Horowitz, J. M., Cardarelli, A. P., \& Sauzier, M. (1990). The aftermath of child sexual abuse: 18 months later. In B. Gomes-Schwartz, J. M. Horowitz, \& A. P. Cardarelli (Eds.), Child sexual abuse: The initial effects. (pp. 132-152). Newbury Park, CA: Sage.

Gomes-Schwartz, B., Horowitz, J. M., \& Sauzier, M. (1985). Severity of emotional distress among sexually abused preschool, school-age, and adolescent children. Hospital and Community Psychiatry, 36 , 503-508.

Goodman, G. S., Taub, E. P., Jones, D. P. H., England, P., Port, L. K., Rudy, L., \& Prado, L. (in press). Emotional effects of criminal court testimony on child sexual assault victims. Monographs of the Society for Research in Child Development. Chicago: University of Chicago.

Hewitt, S. K., \& Friedrich, W. N. (1991, January). Preschool children's responses to alleged sexual abuse at intake and one-year follow up. Paper presented at the meeting of the American Professional Society on the Abuse of Children, San Diego, CA.

Jampole, L., \& Weber, M. K. (1987). An assessment of the behavior of sexually abused and nonsexually abused children with anatomically correct dolls. Child Abuse and Neglect, 11, 187-192.

Kelley, S. J. (1989). Stress responses of children to sexual abuse and ritualistic abuse in day care centers. Journal of Interpersonal Violence, 4, 502-513.

Kelly, R. J. (in press-a). Overall level of distress. In J. Waterman, R. J. Kelly, J. McCord, \& M. K. Oliveri (Eds.), Behind the playground walls: Sexual abuse in preschools. New York: Guilford Press.

Kelly, R. J. (in press-b). Effects on sexuality. In J. Waterman, R. J. Kelly, J. McCord, \& M. K. Oliveri (Eds.), Behind the playground walls: Sexual abuse in preschools. New York: Guilford Press.

Kelly, R. J., \& Ben-Meir, S. (in press). Emotional effects. In J. Waterman, R. J. Kelly, J. McCord, \& M. K. Oliveri (Eds.), Behind the playground walls: Sexual abuse in preschools. New York: Guilford Press.

Kendall-Tackett, K. A. (1991). Characteristics of abuse that influence when adults molested as children seek treatment. Journal of Interpersonal Violence, 6, 486-493.

Kolko, D. J., Moser, J. T., \& Weldy, S. R. (1988). Behavioral/emotional indicators of sexual abuse in child psychiatric inpatients: A controlled comparison with physical abuse. Child Abuse and Neglect, $12,529-541$.

Lanktree, C., \& Briere, J. (1991, January). Early data on the Trauma Symptom Checklist for Children (TSC-C). Paper presented at the meeting of the American Professional Society on the Abuse of Children, San Diego, CA

Lanktree, C., \& Briere, J. (1992, January). Further data on the Trauma Symptom Checklist for Children (TSC-C): Reliability, validity, and sensitivity to treatment. Paper presented at the San Diego Conference on Responding to Child Maltreatment, San Diego, CA.

Lindberg, F., \& Distad, L. (1985). Survival responses to incest: Adolescents in crisis. Child Abuse and Neglect, 9, 521-526.

Lipovsky, J. A., Saunders, B. E., \& Murphy, S. M. (1989). Depression, anxiety, and behavior problems among victims of father-child sexual assault and nonabused siblings. Journal of InterpersonalViolence, 4, 452-468.

Lusk, R. (in press). Cognitive and school-related effects. In J. Waterman, R. J. Kelly, J. McCord, \& M. K. Oliveri (Eds.), Behind the playground walls: Sexual abuse in preschools. New York: Guilford Press.

Mannarino, A. P., \& Cohen, J. A. (1986). A clinical-demographic study of sexually abused children. Child Abuse and Neglect, 10, 17-23.

Mannarino, A. P., Cohen, J. A., \& Gregor, M. (1989). Emotional and behavioral difficulties in sexually abused girls. Journal of Interpersonal Violence, 4, 437-451.
Mannarino, A. P., Cohen, J. A., Smith, J. A., \& Moore-Motily, S. (1991). Six and twelve month follow-up of sexually abused girls. Journal of Interpersonal Violence, 6, 494-511.

McGrath, E., Keita, G. P., Strickland, B. R., \& Russo, N. F. (1990). Women and depression: Risk factors and treatment issues. Washington, DC: American Psychological Association.

McLeer, S. V., Deblinger, E., Atkins, M. S., Foa, E. B., \& Ralphe, D. L. (1988). Post-traumatic stress disorder in sexually abused children. Journal of the American Academy of Child and Adolescent Psychiatry, 27, 650-654.

Mian, M., Wehrspann, W., Klajner-Diamond, H., LeBaron, D., \& Winder, C. (1986). Review of 125 children 6 years of age and under who were sexually abused. Child Abuse and Neglect, 10, 223-229.

Morrow, K. B., \& Sorell, G. T. (1989). Factors affecting self-esteem, depression, and negative behaviors in sexually abused female adolescents. Journal of Marriage and the Family, 51, 677-686.

Newberger, C. M., Gremy, I., \& Waternaux, C. (1990). Mothers and children following sexual abuse disclosure: Connections, boundaries, and the expression of symptomatology. Unpublished manuscript, Children's Hospital, Boston, MA.

Orr, D. P., \& Downes, M. C. (1985). Self-concept of adolescent sexual abuse victims. Journal of Youth and Adolescence, 14, 401-410.

Putnam, F. W. (1990). Disturbances of "self" in victims of childhood sexual abuse. In R. Kluft (Ed), Incest-related syndromes of adult psychopathology (pp. 113-131). Washington, DC: American Psychiatric Press.

Pynoos, R. S., \& Eth, S. (1985). Children traumatized by witnessing acts of personal violence: Homicide, rape, or suicide behavior. In S. Eth \& R. S. Pynoos (Eds.), Post-traumatic stress disorder in children (pp. 19-43). Washington, DC: American Psychiatric Press.

Rimsza, M. E., Berg, R. A., \& Locke, C. (1988). Sexual abuse: Somatic and emotional reactions. Child Abuse and Neglect, 12, 201-208.

Rosenthal, R. (1984). Meta-analytic procedures for social research. Newbury Park, CA: Sage.

Runyan, D. K., Everson, M. D., Edelsohn, G. A., Hunter, W. M., \& Coulter, M. L. (1988). Impact of legal intervention on sexually abused children. Journal of Pediatrics, 113, 647-653.

Sand fort, T. (1982). The sexual aspects of pedophile relations. Amsterdam: Pan/Spartacus.

Sandfort, T. (1984). Sex in pedophiliac relationships: An empirical investigation among a nonrepresentative group of boys. Journal of Sex Research, 20, 123-142.

Shapiro, J. P., Leifer, M., Martone, M. W., \& Kassem, L. (1990). Multimethod assessment of depression in sexually abused girls. Journal of Personality Assessment, 55, 234-248.

Sirles, E. A., Smith, J. A., \& Kusama, H. (1989). Psychiatric status of intrafamilial child sexual abuse victims. Journal of the American Academy of Child and Adolescent Psychiatry, 28, 225-229.

Starr, R. H., MacLean, D. J., \& Keating, D. P. (1991). Life-span development outcomes of child maltreatment. In R. H. Starr \& D. A. Wolfe (Eds.), The effects of child abuse and neglect: Issues and research (pp. 1-32). New York: Guilford Press.

Tong, L., Oates, K., \& McDowell, M. (1987). Personality development following sexual abuse. Child Abuse and Neglect, 11, 371-383.

Valliere, P. M., Bybee, D., \& Mowbray, C. T. (1988, April). Using the Achenbach Child Behavior Checklist in child sexual abuse research: Longitudinal and comparative analysis. Paper presented at the National Symposium on Child Victimization, Anaheim, CA.

Waterman, $\mathbf{J}$. (in press). Mediators of effects on children: What enhances optimal functioning and promotes healing? In J. Waterman, R. J. Kelly, J. McCord, \& M. K. Oliveri (Eds.), Behind the playground walls: Sexual abuse in preschools. New York: Guilford Press. 
Waterman, J., Kelly, R. J., McCord, J., \& Oliveri, M. K. (in press). Behind the playground walls: Sexual abuse in preschools. New York: Guilford Press.

Whitcomb, D., Runyan, D. K., DeVos, E., Hunter, W. M., Cross, T. P., Everson, M. D., Peeler, N. A., Porter, C. A., Toth, P. A., \& Cropper, C. (1991). Child victim as witness research and developmental program (Final report to the Office of Juvenile Justice and Delinquency Prevention, Office of Justice Programs, U.S. Department of Justice). Washington, DC: U. S. Government Printing Office.

White, S., Halpin, B. M., Strom, G. A., \& Santilli, G. (1988). Behavioral comparisons of young sexually abused, neglected, and nonreferred children. Journal of Clinical Child Psychology, 17, 53-61.
White, S., Strom, G. A., Santilli, G., \& Halpin, B. (1986). Interviewing young sexual abuse victims with anatomically correct dolls. Child Abuse and Neglect, 10, 519-529.

Williams, L. (1991). The impact of court testimony on young children: Use of protective strategies in day care cases. Unpublished manuscript, Family Research Laboratory, University of New Hampshire.

Wolfe, V. V., Gentile, C., \& Wolfe, D. A. (1989). The impact of sexual abuse on children: A PTSD formulation. Behavior Therapy, 20, 215228.

Zivney, O. A., Nash, M. R., \& Hulsey, T. L. (1988). Sexual abuse in early versus late childhood: Differing patterns of pathology as revealed on the Rorschach. Psychotherapy, 25, 99-106.

\section{Appendix}

\section{Studies of the Effects of Sexual Abuse on Children}

\begin{tabular}{|c|c|c|c|c|c|c|}
\hline \multirow[b]{2}{*}{ Author } & \multicolumn{3}{|c|}{ Victims } & \multicolumn{3}{|c|}{ Comparison children } \\
\hline & Age & $N$ & Source & Age & $N$ & Source \\
\hline Adams-Tucker (1982) & $2-16$ & 28 & SAT I/E & - & - & - \\
\hline Basta \& Peterson (1990) & $6-10$ & 32 & $\mathrm{I} / \mathrm{E}$ & $6-10$ & 16 & NA-community \\
\hline $\begin{array}{l}\text { Bentovim \& Boston (1988); } \\
\text { Bentovim, vanElberg, \& } \\
\text { Boston (1988) }\end{array}$ & $2-16$ & 411 & SAT I/E & $2-16$ & 362 & NA siblings \\
\hline $\begin{array}{l}\text { Burgess, Hartman, } \\
\text { McCausland, \& Powers } \\
\text { (1984) }\end{array}$ & $6-16$ & 46 & SAT E & - & - & - \\
\hline $\begin{array}{l}\text { Burns, Williams, \& } \\
\text { Finkelhor (1988) }\end{array}$ & $2-5$ & 87 & SAT/day care/E & - & - & - \\
\hline $\begin{array}{l}\text { Caffaro-Rouget, Lang, \& } \\
\text { vanSanten (1989) }\end{array}$ & $1-18$ & 240 & SAT I/E & $2-18$ & 113 & NA-community \\
\hline Cohen \& Mannarino (1988) & $6-12$ & 24 & SAT I/E & - & - & - \\
\hline $\begin{array}{l}\text { Conte \& Schuerman (1987a, } \\
\text { 1987b) }\end{array}$ & $4-17$ & 369 & SAT I/E & $4-17$ & 318 & NA-community \\
\hline $\begin{array}{l}\text { Deblinger, McLeer, Atkins, } \\
\text { Ralphe, \& Foa (1989) }\end{array}$ & $3-13$ & 29 & $\begin{array}{l}\text { Inpatient treatment } \\
\mathrm{I} / \mathrm{E}\end{array}$ & $\begin{array}{l}3-13 \\
3-13\end{array}$ & $\begin{array}{l}29 \\
29\end{array}$ & $\begin{array}{l}\text { Physically abused-inpatient } \\
\text { treatment } \\
\text { NA-inpatient treatment }\end{array}$ \\
\hline $\begin{array}{l}\text { Einbender \& Friedrich } \\
\text { (1989) }\end{array}$ & $6-14$ & 46 & SAT I/E & $6-14$ & 46 & $\mathrm{NA}-$ community \\
\hline Elwell \& Ephross (1987) & $5-12$ & 20 & SAT I/E & - & 一 & - \\
\hline Erickson (1986) & $4-6$ & 11 & $\begin{array}{l}\text { High-risk infant } \\
\text { follow-up }\end{array}$ & $4-6$ & 67 & NA-same group \\
\hline $\begin{array}{l}\text { Everson, Hunter, \& Runyan } \\
\text { (1991) }\end{array}$ & $11-17$ & 44 & SAT I/E & - & - & - \\
\hline $\begin{array}{l}\text { Everson, Hunter, Runyan, } \\
\text { Edelsohn, \& Coulter } \\
\text { (1989) }\end{array}$ & $6-17$ & 88 & SAT I/E & - & - & - \\
\hline Feltman (1985) & $10-17$ & 31 & SAT I & $10-17$ & 24 & NA-outpatient treatment \\
\hline $\begin{array}{l}\text { Friedrich, Beilke, \& Urquiza } \\
\text { (1987) }\end{array}$ & $3-12$ & 93 & SAT I/E & $3-12$ & $\begin{array}{l}64 \\
78\end{array}$ & $\begin{array}{l}\text { NA-outpatient treatment } \\
\text { NA-community }\end{array}$ \\
\hline $\begin{array}{l}\text { Friedrich, Beilke, \& Urquiza } \\
\text { (1988) }\end{array}$ & $3-8$ & 33 & SAT I/E & - & - & - \\
\hline Friedrich \& Luecke (1988) & $\begin{array}{l}4-11 \\
5-13\end{array}$ & $\begin{array}{l}22 \\
22\end{array}$ & $\begin{array}{l}\mathrm{SAT} / \mathrm{I} / \mathrm{E}^{\mathrm{b}} \\
\mathrm{SAT} \mathrm{I} / \mathrm{E}^{\mathrm{c}}\end{array}$ & - & - & - \\
\hline Friedrich \& Reams (1987) & $3-7$ & 8 & SAT I/E & - & - & - \\
\hline $\begin{array}{l}\text { Friedrich, Urquiza, \& Beilke } \\
\text { (1986) }\end{array}$ & $3-12$ & 85 & SAT I/E & Norms & - & - \\
\hline $\begin{array}{l}\text { Gale, Thompson, Moran, \& } \\
\text { Sack (1988) }\end{array}$ & $<7$ & 37 & SAT I/E & $<7$ & $\begin{array}{l}35 \\
13\end{array}$ & $\begin{array}{l}\text { NA-outpatient treatment } \\
\text { Physically abused- } \\
\text { outpatient treatment }\end{array}$ \\
\hline $\begin{array}{l}\text { Gomes-Schwartz, Horowitz, } \\
\text { \& Sauzier (1985); Gomes- } \\
\text { Schwartz, Horowitz, }\end{array}$ & $4-18$ & 113 & SAT I/E & $\begin{array}{l}\text { Clinical and } \\
\text { nonclinical } \\
\text { norms }\end{array}$ & & \\
\hline
\end{tabular}




\begin{tabular}{|c|c|c|c|c|c|c|}
\hline \multirow[b]{2}{*}{ Author } & \multicolumn{3}{|c|}{ Victims } & \multicolumn{3}{|c|}{ Comparison children } \\
\hline & Age & $N$ & Source & Age & $N$ & Source \\
\hline \multicolumn{7}{|l|}{$\begin{array}{l}\text { Cardarelli, \& Sauzier } \\
\text { (1990) }\end{array}$} \\
\hline Jampole \& Weber (1987) & $3-8$ & 10 & SAT/NR & $3-8$ & 10 & NA-community \\
\hline Kelley (1989) & $4-11$ & $\begin{array}{l}32 \\
35\end{array}$ & $\begin{array}{l}\text { Day care } \\
\text { Ritualistically } \\
\text { abused in day } \\
\text { care/E }\end{array}$ & $4-11$ & 67 & NA-day care \\
\hline $\begin{array}{l}\text { Kelly (in press-a, in press-b); } \\
\text { Kelly \& Ben-Meir (in } \\
\text { press); Lusk (in press) }\end{array}$ & $\begin{array}{l}4-14 \\
15\end{array}$ & 69 & $\begin{array}{l}\text { Ritualistically } \\
\text { abused in day } \\
\text { care/SA/E }\end{array}$ & $5-14$ & 32 & NA-day care \\
\hline $\begin{array}{l}\text { Kolko, Moser, \& Weldy } \\
\text { (1988) }\end{array}$ & $5-14$ & $\begin{array}{r}7 \\
22\end{array}$ & $\begin{array}{l}\text { SA/inpatient } \\
\text { treatment/I/E } \\
\text { SA and physically } \\
\text { abused }\end{array}$ & $\begin{array}{l}5-14 \\
5-14\end{array}$ & $\begin{array}{l}44 \\
30\end{array}$ & $\begin{array}{l}\text { NA-inpatient treatment } \\
\text { Physically abused-inpatient } \\
\text { treatment }\end{array}$ \\
\hline Lindberg \& Distad (1985) & $12-18$ & 27 & Children's home/I & 一 & - & - \\
\hline $\begin{array}{l}\text { Lipovsky, Saunders, \& } \\
\text { Murphy (1989) }\end{array}$ & $M=12.2$ & 100 & SAT I & $M=12.3$ & 100 & NA siblings \\
\hline Mannarino \& Cohen (1986) & $3-16$ & 45 & SAT I/E & - & - & $\cdot \cdot$ \\
\hline $\begin{array}{l}\text { Mannarino, Cohen, \& } \\
\text { Gregor (1989) }\end{array}$ & $6-12$ & 94 & SAT I/E & $6-12$ & $\begin{array}{l}89 \\
75\end{array}$ & $\begin{array}{l}\text { NA-outpatient treatment } \\
\text { NA-community }\end{array}$ \\
\hline $\begin{array}{l}\text { McLeer, Deblinger, Atkins, } \\
\text { Foa, \& Ralphe (1988) }\end{array}$ & $3-16$ & 31 & SAT I/E & - & - & - \\
\hline $\begin{array}{l}\text { Mian, Wehrspann, Klajner- } \\
\text { Diamond, LeBaron, \& } \\
\text { Winder (1986) }\end{array}$ & $<6$ & 125 & Chart review I/E & 一 & - & - \\
\hline Morrow \& Sorell (1989) & $12-18$ & 101 & SAT I & - & - & - \\
\hline $\begin{array}{l}\text { Newberger, Gremy, \& } \\
\text { Waternaux (1990) }\end{array}$ & $6-12$ & 49 & SAT I & $一$ & - & - \\
\hline Orr \& Downes (1985) & $9-15$ & 20 & SAT $\mathbf{l} / \mathrm{E}$ & $9-15$ & 20 & NA-emergency room pop \\
\hline $\begin{array}{l}\text { Rimsza, Berg, \& Locke } \\
(1988)\end{array}$ & $2-17$ & 72 & $\begin{array}{l}\mathrm{SAT} \mathrm{I} / \mathrm{E} / \mathrm{chart} \\
\text { review }\end{array}$ & $2-17$ & 72 & NA-clinic/chart review \\
\hline $\begin{array}{l}\text { Runyan, Everson, Edelsohn, } \\
\text { Hunter, \& Coulter (1988) }\end{array}$ & $6-17$ & 75 & SAT $1 / E$ & - & - & - \\
\hline $\begin{array}{l}\text { Shapiro, Leifer, Martone, \& } \\
\text { Kassem (1990) }\end{array}$ & $5-16$ & 53 & SAT I/E & $3-16$ & 70 & NA-outpatient treatment \\
\hline $\begin{array}{l}\text { Sirles, Smith, \& Kusama } \\
\text { (1989) }\end{array}$ & $2-17$ & 207 & SAT I/E & - & - & - \\
\hline $\begin{array}{l}\text { Tong, Oates, \& McDowell } \\
\text { (1987) }\end{array}$ & $3-16$ & 49 & SAT I/E & $3-16$ & 49 & NA-community \\
\hline $\begin{array}{l}\text { Valliere, Bybee, \& Mowbray } \\
\text { (1988) }\end{array}$ & $4-13$ & 34 & Day care/E & $5-11$ & 136 & $\begin{array}{l}\text { NA-community } \\
\text { Norms }\end{array}$ \\
\hline $\begin{array}{l}\text { White, Halpin, Strom, \& } \\
\text { Santilli (1988) }\end{array}$ & $2-6$ & 17 & SAT/NR & $2-6$ & $23 / 18$ & NA-community/neglect \\
\hline $\begin{array}{l}\text { White, Strom, Santilli, \& } \\
\text { Halpin (1986) }\end{array}$ & $2-6$ & 25 & $\mathrm{SAT} / \mathrm{NR}$ & $2-6$ & 25 & NA-community \\
\hline $\begin{array}{l}\text { Wolfe, Gentile, \& Wolfe } \\
(1989)\end{array}$ & $5-16$ & 71 & SAT I/E & 一 & - & 一 \\
\hline $\begin{array}{l}\text { Zivney, Nash, \& Hulsey } \\
\text { (1988) }\end{array}$ & $3-16$ & 80 & SAT I/E & $3-16$ & 70 & NA-outpatient treatment \\
\hline
\end{tabular}

Note. $\mathrm{SAT}=$ sexual abuse treatment or evaluation (outpatient unless indicated), $\mathrm{I}=$ intrafamilial abuse, $\mathrm{E}=$ extrafamilial abuse, $\mathrm{NR}=\mathrm{data}$ not reported, $\mathrm{SA}=$ sexually abused, pop = population.

${ }^{a}$ Children in sex rings. ${ }^{b}$ Sexually aggressive victims. ${ }^{\mathbf{c}}$ Nonsexually aggressive victims.

Received May 28, 1991

Revision received March 30, 1992

Accepted March 30, 1992 